\title{
Systemic Mastocytosis Associated with Splenic Marginal Zone Lymphoma with Villous Lymphocytes
}

\author{
R. Fernández-Torres, ${ }^{1}$ M. M. Verea, ${ }^{1}$ A. Álvarez, ${ }^{2}$ P. Torres, ${ }^{3}$ and E. Fonseca ${ }^{1}$ \\ ${ }^{1}$ Departments of Dermatology, Complejo Hospitalario Universitario A Coruña, Sir John Moore S/N, 15001 La Coruña, Spain \\ ${ }^{2}$ Departments of Pathology, Complejo Hospitalario Universitario A Coruña, Sir John Moore S/N, 15001 La Coruña, Spain \\ ${ }^{3}$ Departments of Haematology, Complejo Hospitalario Universitario A Coruña, Sir John Moore S/N, 15001 La Coruña, Spain
}

Correspondence should be addressed to R. Fernández-Torres, rosaftorres@gmail.com

Received 22 November 2010; Revised 5 June 2011; Accepted 9 June 2011

Academic Editor: Dražen Jukić

Copyright (C 2011 R. Fernández-Torres et al. This is an open access article distributed under the Creative Commons Attribution License, which permits unrestricted use, distribution, and reproduction in any medium, provided the original work is properly cited.

The development of a second haematological disease during the course of systemic mastocytosis is a well-known phenomenon. In most of the cases, they consist of myelodysplasia or myeloproliferative disorders. The association with lymphoproliferative disorders has also been described, but it is uncommon and the relationship is not well established. We report a patient diagnosed with systemic mastocytosis who three years later developed a splenic marginal zone lymphoma with villous lymphocytes.

\section{Introduction}

The term mastocytosis refers to a group of disorders characterized by and abnormal growth and accumulation of mast cells in one or more organs, including skin, lymph nodes, bone marrow, nervous system, gastrointestinal tract, spleen, and liver.

Systemic mastocytosis associated with clonal haematological nonmast cell lineage disease (SM-AHNMD) is an entity recognized by the World Health Organization classification of tumours of hematopoietic tissues [1].

The occurrence of myeloproliferative syndromes in patients with systemic mastocytosis is a well-recognized phenomenon. However, non-Hodgkin's lymphoma is very uncommon.

We report a patient with urticaria pigmetosa of ten years evolution and systemic mastocytosis (SM) diagnosed three years ago who developed splenic marginal zone lymphoma with villous lymphocytes, a low-grade B-cell non-Hodgkin's lymphoma characterized by splenomegaly, moderate lymphocytosis, bone marrow infiltration, serum monoclonal band, and a benign course with response to splenectomy [2].
To our knowledge, the association of this neoplasm with SM has not been previously documented in the literature.

\section{Case Report}

A 65-year-old female with unremarkable past medical history presented with papular, purplish, and itchy cutaneous lesions located on her forearms, thighs, and trunk for ten years (Figure 1).

Laboratory investigations, including blood counts, chemistry, and routine coagulation parameters, showed no alterations. A skin biopsy from a papular lesion revealed an acanthotic epidermis and hyperpigmentation of the epidermal basal cell layer. Giemsa stain showed many mast cells around blood vessels and scattered throughout the dermis.

A bone marrow smear showed atypical large, spindleshaped, and hypogranulated mast cells with elongated nucleus. The histological examination of a bone marrow biopsy disclosed decreased cellularity and multifocal infiltrates of cells with oval nucleus and large cytoplasm. These cells were positive with the monoclonal mast cell stain 


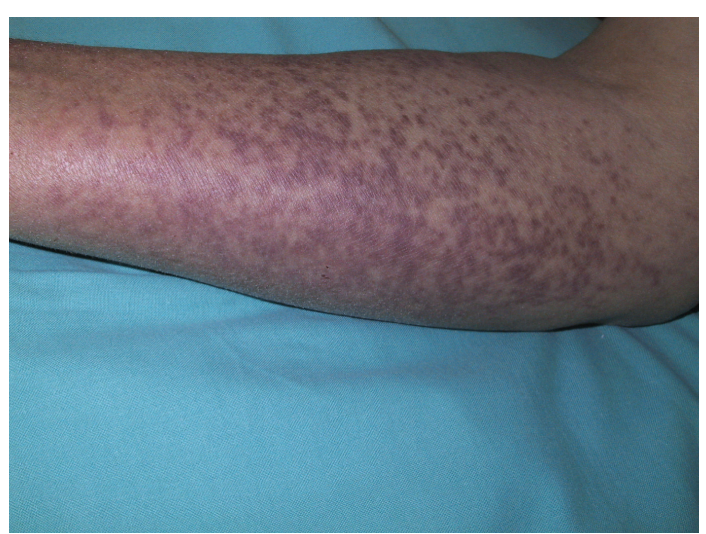

Figure 1: Papular, purplish cutaneous lesions of urticaria pigmentosa on the forearms.

and located surrounding blood vessels or with interstitial distribution. Surrounding these cells, small lymphocytic aggregates were observed.

According to the cutaneous findings and the bone marrow infiltration, the diagnosis of systemic mastocytosis was made.

Because of a moderate pruritus, the patient was treated with $\mathrm{H}_{1}$-receptor blocking agents.

Three years later, a routine laboratory examination showed anaemia, lymphocytosis, increased $\beta 2$-microglobulin $(2.54 \mathrm{mg} / \mathrm{l}$, normal value: $1.5-2.3)$, and a serum monoclonal band of lambda light chains. Physical examination showed hepatosplenomegaly and lymphadenopathy, which was confirmed by an abdominal echography.

Peripheral blood smear showed morphologically abnormal lymphocytes with elongated cytoplasmic extensions (Figure 2). Immunohistochemical studies disclosed a B immunophenotype characterized by the expression of CD22, FMC7, CD20, and slight expression of CD11c, CD10, CD38, and negative for CD5 and CD23.

A new bone marrow biopsy showed nodular infiltration by atypical mast cells and nodular interstitial infiltration by lymphoid cells positive with CD 20 stain (Figure 3 ).

These features were consistent with the diagnosis of splenic marginal zone lymphoma with villous lymphocytes. Thus, the diagnosis of systemic mastocytosis with coexisting splenic marginal zone lymphoma with villous lymphocytes was established.

She received chemotherapy with chlorambucil for 28 months with progressive improvement of laboratory test and parallel clearing of trunk cutaneous lesions, but not on the forearms and thighs. Two new skin biopsies of persistent lesions and cleared skin showed similar number of mast cells in both.

\section{Discussion}

A significant number of patients with systemic mastocytosis (5-40\%) may develop an associated haematological clonal nonmast cell lineage disease (SM-AHNMD). Both neoplasms are usually synchronously diagnosed on the basis of

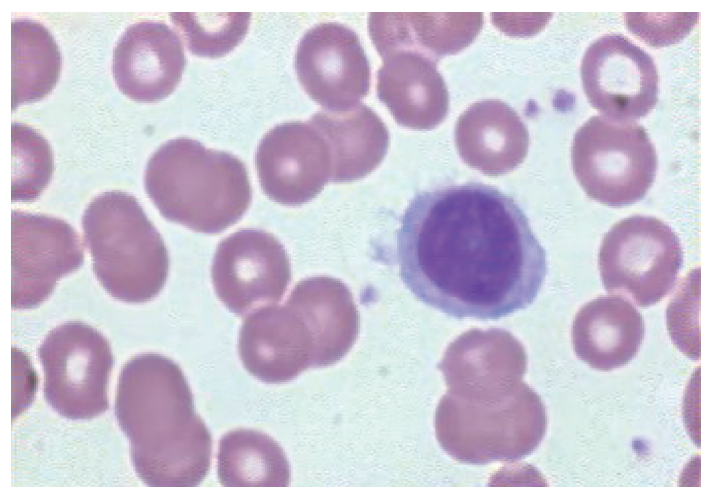

Figure 2: Peripheral blood smear showing an atypical lymphocyte with elongated cytoplasm processes.

morphological evaluation of a bone marrow biopsy, although later development of AHNMD in patients with long standing mastocytosis, as in our patient, is also possible [3].

Any type of haematological malignancy may be associated with SM. However, myeloid neoplasms develop with a much higher frequency than lymphoid neoplasms $[4,5]$. Among 138 cases of SM-AHNMD reported by Pardanani et al., $123(89 \%)$ had associated myeloid neoplasm and only 7 (5\%) had lymphoma [6].

The pathophysiologic basis of simultaneous occurrence of SM and other neoplasms is not completely understood. In the case of myeloid neoplasms, the first possibility is that a hematopoietic progenitor cell, capable of given rise to mast cells and other myeloid cells, is involved. In this case, two clinically distinct disorders develop due to subclone formation [7]. It has also been suggested that mast cells may produce growth factors capable of stimulating the proliferation of other cell lines $[8,9]$.

The codevelopment of SM and lymphoid malignancies, due to the small number of cases reported, may be incidental or may occur as a result of genetic instability.

Kim et al. demonstrated distinct clonal origins in mastocytosis and associated B-cell lymphomas [10]. However, there is evidence suggesting that B cells share a common progenitor with macrophages, a cell lineage that appears to be closely related to mastocytes, and c-Kit mutations have been detected in B lymphocytes, apart from neoplastic mastocytes, so the same origin of both neoplasm is another possibility [11].

Patients with SM and lymphoproliferative diseases usually have a long history of indolent SM, which suggests a different pathogenesis for the two entities. In our case, NHL developed three years after the diagnosis of SM in a patient with urticaria pigmentosa of ten years evolution.

Treatment and prognosis of SM-AHNMD depend on the associated haematological disease. Chemotherapy usually affects the associated haematological neoplasm with little or no effect on mast cell disease $[12,13]$. In our patient, improvement of cutaneous lesions on the trunk was observed after treatment with chlorambucil, but histological examination showed no decrease in the number of mast cells. The significance of this fact is not well understood, and it 


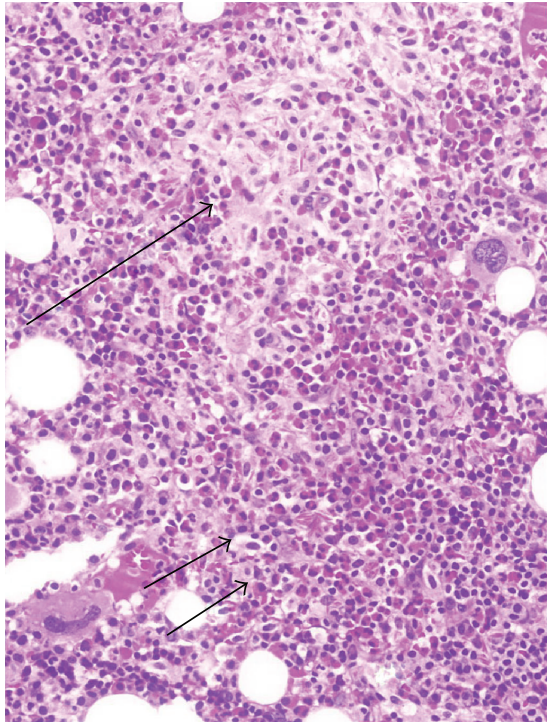

(a)

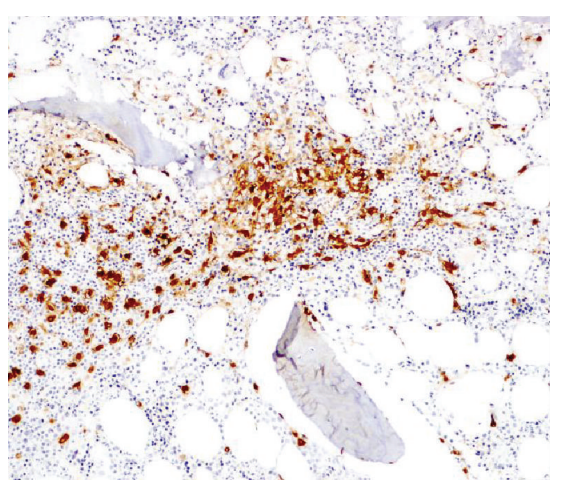

(b)

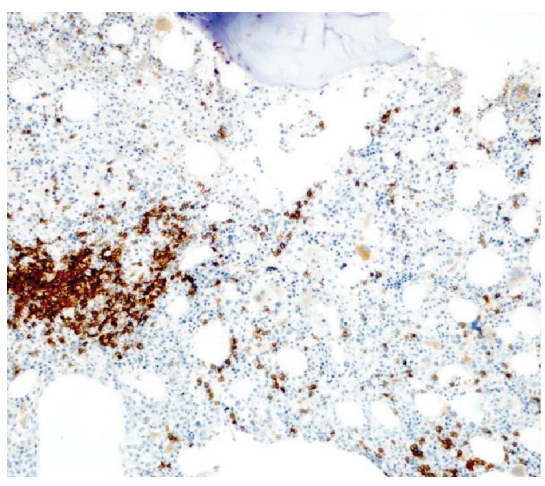

(c)

FIgURE 3: (a) Bone marrow biopsy with areas of infiltration by villous lymphocytes ( 2 arrows) and areas of infiltration by mast cells and fibrosis (arrow) (haematoxylin-eosin, original magnification $\times 200$ ). (b) Areas of mast cell infiltration in the bone marrow (Mast cell stain $\times 150$ ). (c) Villous lymphocytes in the bone marrow (CD20 stain $\times 150)$.

might be associated with a poor prognosis in patients with associated hematologic disorders [14]. It is believed that it may be a natural process in the evolution of SM or could be related with a change in homing receptor mast cells.

\section{Conclusion}

In summary, we report a case of SM-AHNMD, with the peculiarity that the associated neoplasm was a splenic marginal zone lymphoma, an association of which we have found no previous reports in the literature.

\section{Conflict of Interests}

The authors declare that they have no conflict of interests.

\section{References}

[1] H. P. Horny, D. D. Metcalfe, J. M. Bennett et al., "Mastocytosis," in WHO Classification of Tumors of Hematopoietic and Lymphoid Tissues, S. H. Swerdlow, E. Campo, N. L. Harris et al., Eds., pp. 54-63, International Agency for Research and Cancer, Lyon, France, 4th edition, 2008.

[2] D. Catovsky and E. Matutes, "Splenic lymphoma with circulating villous lymphocytes/splenic marginal-zone lymphoma," Seminars in Hematology, vol. 36, no. 2, pp. 148-154, 1999.

[3] H. P. Horny, K. Sotlar, W. R. Sperr, and P. Valent, "Systemic mastocytosis with associated clonal haematological non-mast cell lineage diseases: a histopathological challenge," Journal of Clinical Pathology, vol. 57, no. 6, pp. 604-608, 2004.

[4] W. R. Sperr, H. P. Horny, K. Lechner, and P. Valent, "Clinical and biologic diversity of leukemias occurring in patients with mastocytosis," Leukemia and Lymphoma, vol. 37, no. 5-6, pp. 473-486, 2000.

[5] H. P. Horny, M. Ruck, M. Wehrmann, and E. Kaiserling, "Blood findings in generalized mastocytosis: evidence of frequent simultaneous occurrence of myeloproliferative disorders," British Journal of Haematology, vol. 76, no. 2, pp. 186193, 1990.

[6] A. Pardanani, K. H. Lim, T. L. Lasho et al., "Prognostically relevant breakdown of 123 patients with systemic mastocytosis associated with other myeloid malignancies," Blood, vol. 114, no. 18, pp. 3769-3772, 2009.

[7] W. D. Travis, C. Y. Li, E. J. Bergstralh, L. T. Yam, and R. G. Swee, "Systemic mast cell disease. Analysis of 58 cases and literature review," Medicine, vol. 67, no. 6, pp. 345-368, 1988.

[8] W. D. Travis, C. Y. Li, L. T. Yam, E. J. Bergstralh, and R. G. Swee, "Significance of systemic mast cell disease with associated hematologic disorders," Cancer, vol. 62, no. 5, pp. 965-972, 1988.

[9] K. Sotlar, T. Marafioti, H. Griesser et al., "Detection of ckit mutation Asp 816 to Val in microdissected bone marrow infiltrates in a case of systemic mastocytosis associated with chronic myelomonocytic leukaemia," Journal of Clinical Pathology, vol. 53, no. 4, pp. 188-193, 2000.

[10] Y. Kim, L. M. Weiss, Y. Y. Chen, and V. Pullarkat, "Distinct clonal origins of systemic mastocytosis and associated B-cell lymphoma," Leukemia Research, vol. 31, no. 12, pp. 1749$1754,2007$.

[11] C. Akin, A. S. Kirshenbaum, T. Semere, A. S. Worobec, L. M. Scott, and D. D. Metcalfe, "Analysis of the surface expression of c-kit and occurrence of the c-kit Asp816Val activating mutation in $\mathrm{T}$ cells, B cells, and myelomonocytic cells in patients with mastocytosis," Experimental Hematology, vol. 28, no. 2, pp. 140-147, 2000.

[12] R. I. Parker, "Hematologic aspects of mastocytosis: II: management of hematologic disorders in association with systemic 
mast cell disease," Journal of Investigative Dermatology, vol. 96, no. 3, 1991.

[13] A. S. Worobec, "Treatment of systemic mast cell disorders," Hematology/Oncology Clinics of North America, vol. 14, no. 3, pp. 659-687, 2000.

[14] K. Brockow, L. M. Scott, A. S. Worobec et al., "Regression of urticaria pigmentosa in adult patients with systemic mastocytosis: correlation with clinical patterns of disease," Archives of Dermatology, vol. 138, no. 6, pp. 785-790, 2002. 


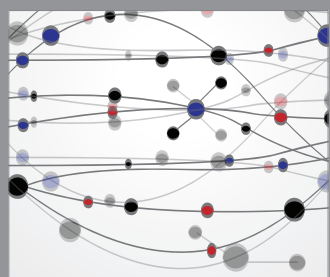

The Scientific World Journal
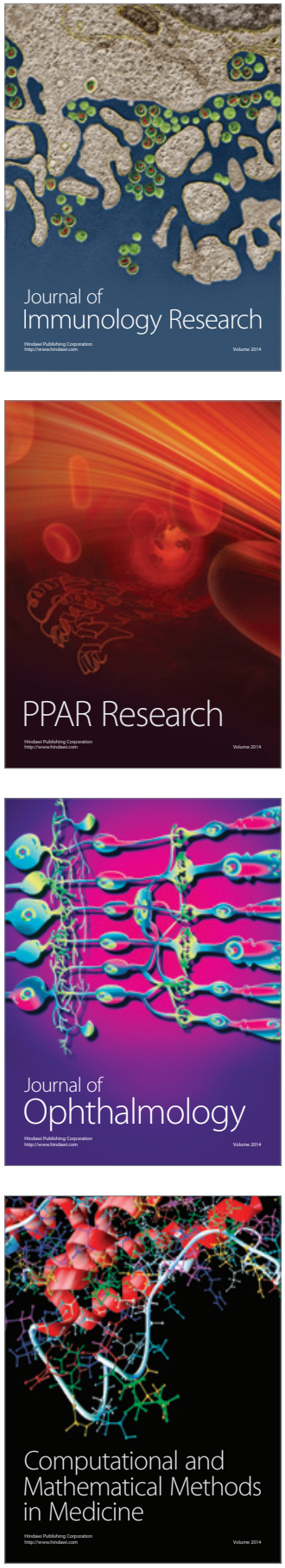

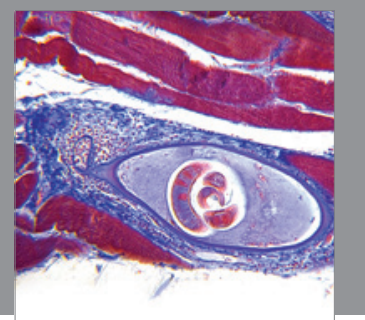

Gastroenterology

Research and Practice
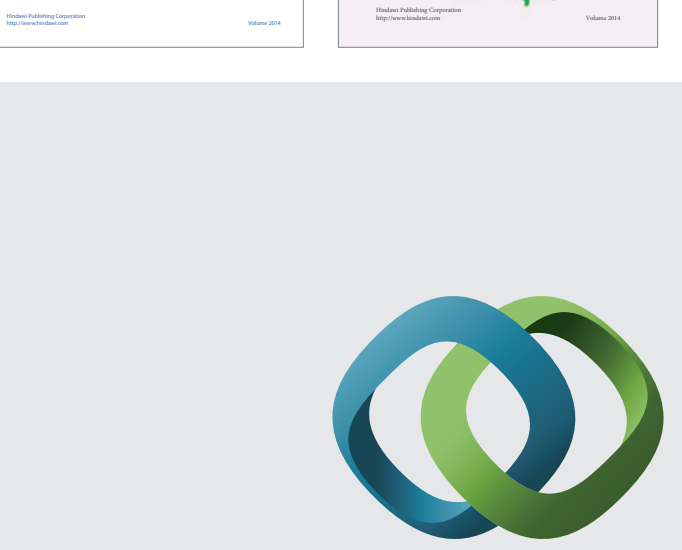

\section{Hindawi}

Submit your manuscripts at

http://www.hindawi.com
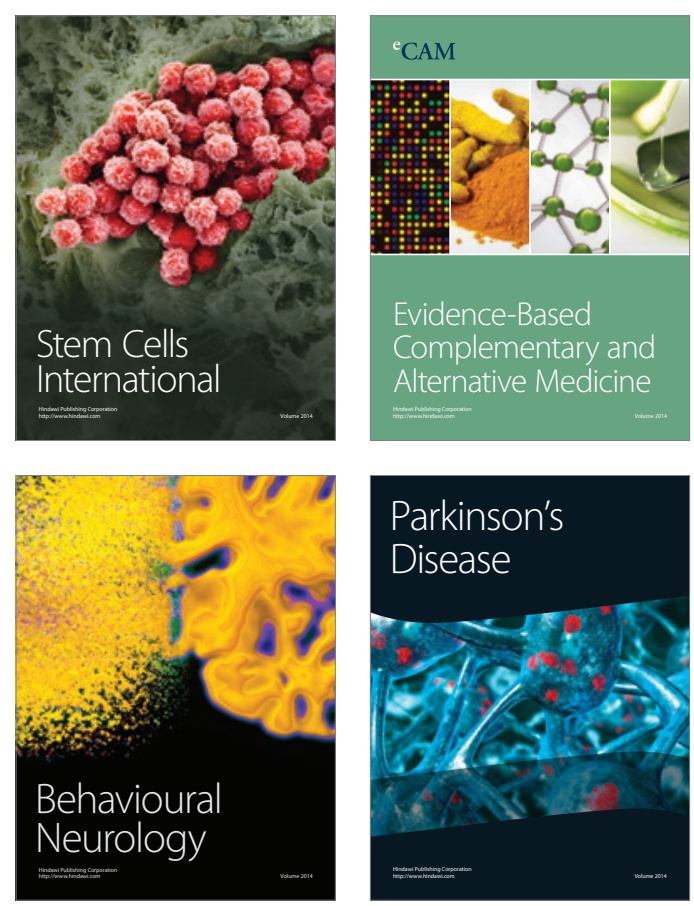

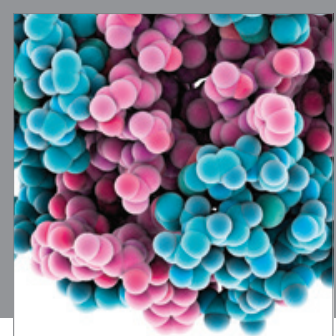

Journal of
Diabetes Research

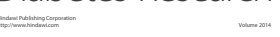

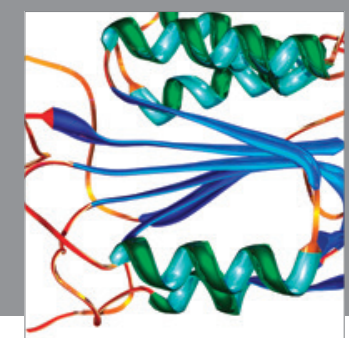

Disease Markers
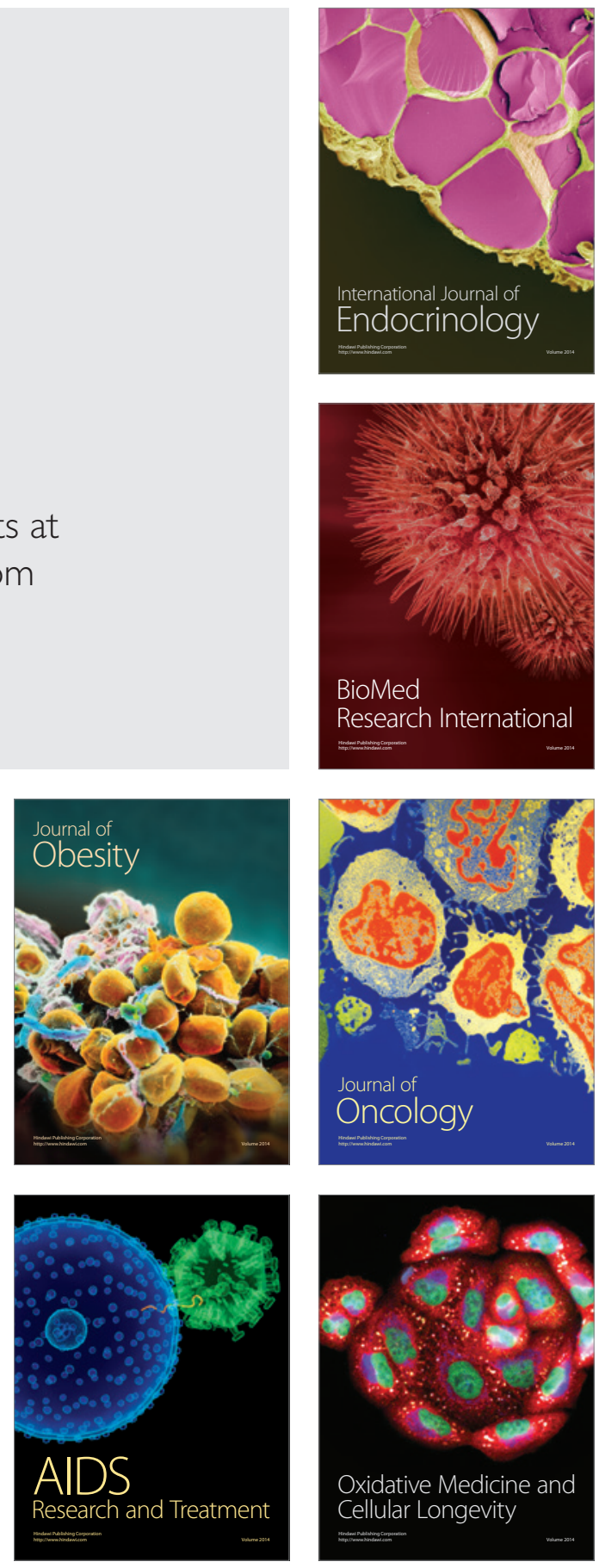